\begin{tabular}{ll|l} 
Case Reports in & \multicolumn{2}{c}{ Case Rep Gastroenterol 2018;12:551-555 } \\
\cline { 2 - 3 } Gastroenterology & $\begin{array}{l}\text { DOl: 10.1159/000444520 } 2018 \text { The Author(s) } \\
\text { Published online: September 18, 2018 }\end{array}$ & $\begin{array}{l}\text { Published by S. Karger AG, Basel } \\
\text { www.karger.com/crg }\end{array}$ \\
\cline { 2 - 3 } & $\begin{array}{l}\text { This article is licensed under the Creative Commons Attribution-NonCommercial } 4.0 \\
\text { International License (CC BY-NC) (http://www.karger.com/Services/OpenAccessLicense). } \\
\text { Usage and distribution for commercial purposes requires written permission. }\end{array}$
\end{tabular}

\title{
Appendiceal Perforation due to Migration of a Dental Instrument
}

\author{
Ryoichi Tsukamoto Shozo Miyano Michio Machida \\ Toshiaki Kitabatake Minoru Fujisawa Kuniaki Kojima \\ Department of General Surgery, Juntendo Nerima Hospital, Tokyo, Japan
}

\section{Keywords}

Appendiceal perforation - Acute appendicitis · Dental instrument

\begin{abstract}
A 40-year-old male without any past medical history accidentally swallowed a titanium dental instrument (reamer) for root canal treatment. A cathartic was prescribed at a local hospital, and the course was observed. However, since the reamer was not excreted in feces, he was referred to our hospital. After admission, CT, lower gastrointestinal endoscopy, and barium enema revealed the migration of a foreign body into the appendix and its protrusion into the intraperitoneal cavity. As an emergency operation, laparoscopic appendectomy including the foreign body was performed. The following course was favorable without postoperative complications, and he was discharged on the 2 nd hospital day. We report a patient with appendiceal perforation due to a foreign body (dental instrument for root canal treatment) in the appendix.
\end{abstract}

(c) 2018 The Author(s)

Published by S. Karger AG, Basel

\section{Introduction}

Among the differential diagnoses of acute abdomen, acute appendicitis is the most frequently observed and a very important one. As a cause of acute appendicitis, migration of a foreign body was reported [1]. Ingested foreign bodies are generally excreted in feces spontaneously, but are retained in the gastrointestinal tract in about $1 \%[1,2]$, inducing com- 


\section{Case Reports in Gastroenterology}

Case Rep Gastroenterol 2018;12:551-555

DOI: 10.1159/000444520

(c) 2018 The Author(s). Published by S. Karger AG, Basel www.karger.com/crg

Tsukamoto et al.: Appendiceal Perforation due to Migration of a Dental Instrument

plications such as gastrointestinal perforation. In particular, migration into the appendix is extremely rare because of the narrow orifice of the appendix. We report a patient with appendiceal perforation due to a foreign body in the appendix.

\section{Case Presentation}

A 40-year-old male with no medical history was admitted. He accidentally ingested a titanium dental instrument (reamer) for root canal treatment. A cathartic was prescribed at a local hospital, and the course was observed. However, since the reamer was not excreted in feces, he was referred to our hospital.

On physical examination at the first visit, he was conscious. His blood pressure was $108 / 75 \mathrm{~mm} \mathrm{Hg}$, his heart rate was $73 \mathrm{bpm}$, and his body temperature was $36.7^{\circ} \mathrm{C}$. The abdomen was flat and soft, and there was no abdominal pain, tenderness, or rebound tenderness. Laboratory data show that the WBC count was slightly increased $(9,700 / \mu \mathrm{L})$, but there were no other abnormalities.

Plain abdominal radiography shows neither an abnormal gas image nor free air. There was an area with decreased radiolucency (about $3 \mathrm{~cm}$ ) in the right lower abdominal area. Abdominal contrast-enhanced CT was performed. The size of the appendix was $7 \mathrm{~mm}$, but no clear thickening of the wall was observed. A linear high attenuation shadow protruding from the appendix was present (Fig. 1). There was neither ascites retention nor free air.

Fluoroscopy-guided lower gastrointestinal endoscopy shows that the appendiceal orifice was open, but no clear foreign body was observed. Vermography performed from the appendiceal root showed migration of a foreign body into the appendix and extraappendiceal protrusion of its tip (Fig. 2). A diagnosis of perforated appendicitis due to a foreign body in the appendix was made, and emergency laparoscopic appendectomy was performed.

When the abdominal cavity was observed, no protrusion of the tip of the foreign body was noted. After the mesoappendix was cut using laparoscopic coagulation shears, the appendiceal root was cut using an ENDO-GIA White $(45-2.5)^{\circledR}$. When the resected appendix was opened, a foreign body $(33 \mathrm{~mm}$ ) penetrating to the mesoappendix side was observed. There was no macroscopically clear inflammation (Fig. 3). Histopathologically, the size of the resected appendix was $7 \times 8 \times 68 \mathrm{~mm}$. Inflammatory cell infiltration and fibrosis were only partly present. His postoperative course was favorable, and he was discharged on the 2 nd hospital day.

\section{Discussion}

The incidence of migration of a gastrointestinal foreign body into the appendix is $0.2-$ $0.75 \%$ due to the small orifice of the appendix [3]. Appendiceal perforation due to gastrointestinal foreign bodies is considered to be extremely rare.

In our patient, the foreign body was a titanium dental instrument (reamer) for dental canal treatment. Foreign bodies causing gastrointestinal perforation are associated with dietary habits in Japan and are mostly fish bone (44-65\%) [4].

For diagnosis, CT is the most useful, showing a detection rate of $60-63 \%$. Foreign bodies are visualized as high attenuation areas [5]. In our patient, since the foreign body was a metal instrument, the diagnosis was straightforward. A search of the PubMed revealed no report of appendicitis due to migration of a titanium dental instrument (reamer) for root canal treatment, and our case may be the first. 
The following 4 mechanisms of foreign body appendicitis and appendiceal perforation have been suggested: (1) a foreign body stimulates the appendiceal mucosa, and inflammatory reactions extend from this site, inducing appendicitis. (2) A foreign body is caught, and reactions to it induce lymph follicle hyperplasia, resulting in obstruction of the appendiceal lumen, or the foreign body itself obstructs the appendiceal lumen, inducing appendicitis. (3) A sharp foreign body perforates the appendix without inflammatory reactions in the appendiceal mucosa. (4) A foreign body stimulating the mucosa only slightly is retained without causing symptoms for a long period, resulting in chronic pathological inflammation [6]. The mechanism in our patient may be classified as that mentioned under point 3 above.

When the foreign body has a sharp tip, as in our patient, perforation occurs in $70 \%$, and abscess formation occurs in $31 \%$ [7, 8]. Therefore, even when there are no symptoms, appendectomy is appropriate in the presence of protrusion of the foreign body into the intraperitoneal cavity. Finally, detailed history-taking and the appropriate evaluation of examination findings are important.

\section{Statement of Ethics}

The authors have no ethical conflicts to disclose.

\section{Disclosure Statement}

The authors have no conflicts of interest to disclosure.

\section{References}

1 Gracia C, Frey CF, Bodai BI: Diagnosis and management of ingested foreign bodies: a ten-year experience. Ann Emerg Med 1984;13:30-34.

2 Selivanou V, Scheldon G, Cello J, et al: Management of foreign body ingestion. Ann Surg 1984;199:187191.

3 Toyota H, Moriya T, Momose R, et al: A patient with an appendiceal abscess due to dentures. J Jpn Pract Surg Soc 1991;52:2132-2135.

4 Hanamoto T, Inoue Y, Sunahara M, et al: A patient with appendiceal perforation due to fish bone. J Jpn Pract Surg Soc 2008;69:576-580.

5 Yo K, Inoue S, Watanabe Y, et al: A patient with preoperatively diagnosed ileac perforation due to fish bone - analysis of 271 patients with gastrointestinal perforation due to fish bone during the previous 10-year period. Gastroenterol Surg 2001;34:1640-1644.

6 Terauchi M, Ozawa A, Ishibashi H: A patient with acute appendicitis due to a tooth accidentally ingested 8 years earlier. J Jpn Pract Surg Soc 2005;66:2209-2212.

7 Balch CM, Silver D: Foreign bodies in the appendix. Report of eight cases and review of the literature. Arch Surg 1971;102:14-21.

8 Sukhotnik I, Klin B, Siplovich L: Foreign body appendicitis. J Pediatr Surg 1995;30:1515-1516. 


\section{Case Reports in Gastroenterology

\begin{tabular}{l|l}
\hline Case Rep Gastroenterol 2018;12:551-555 \\
\hline DOI: 10.1159/000444520 & $\begin{array}{l}\text { @ 2018 The Author(s). Published by S. Karger AG, Basel } \\
\text { www.karger.com/crg }\end{array}$ \\
\hline
\end{tabular} \\ Tsukamoto et al.: Appendiceal Perforation due to Migration of a Dental Instrument}

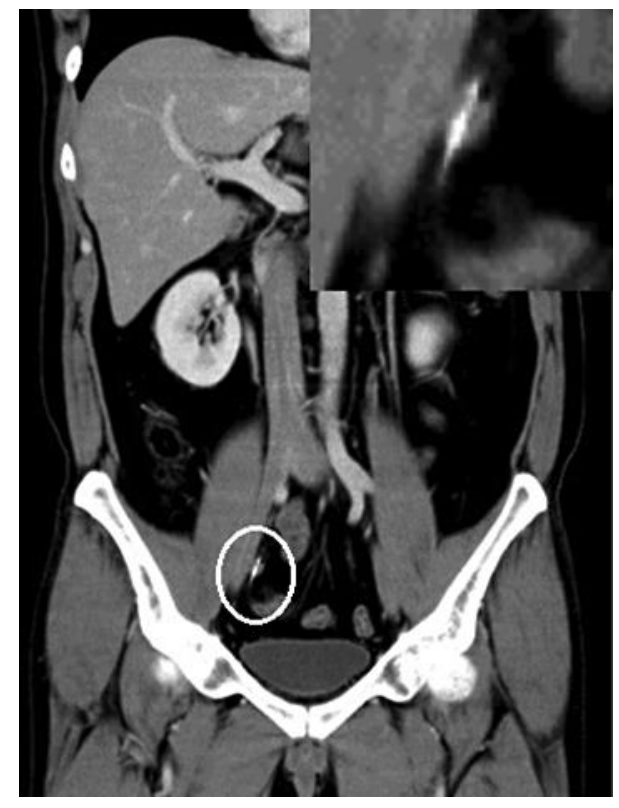

Fig. 1. Intraperitoneal protrusion of the tip of the foreign body was suspected.

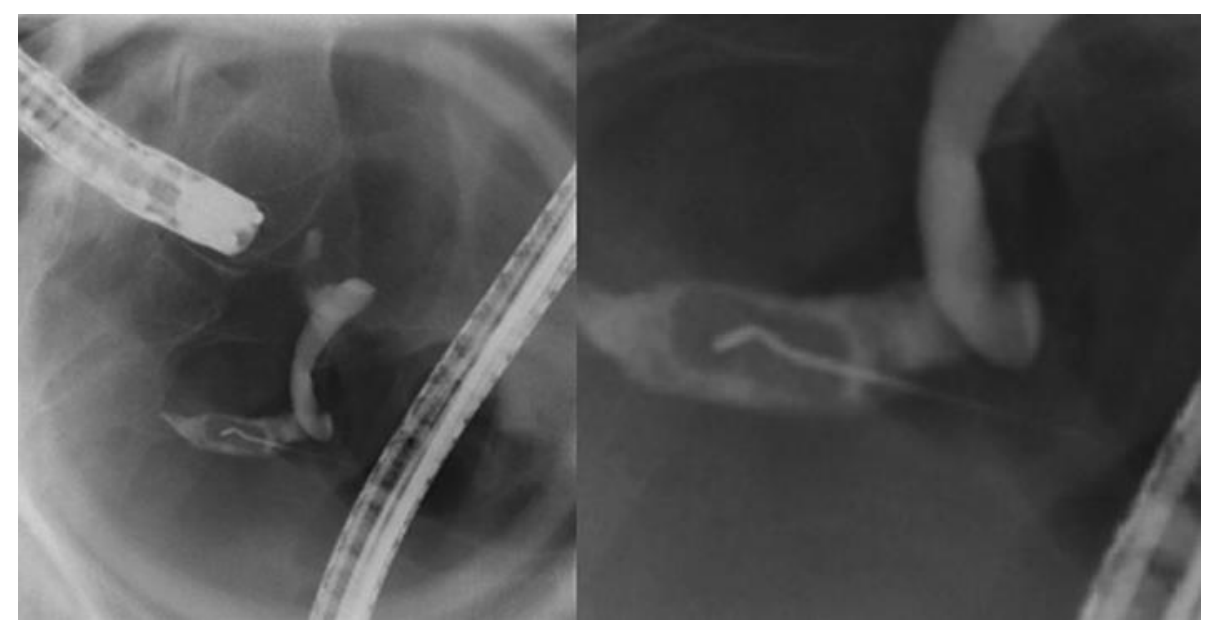

Fig. 2. The tip of the foreign body perforating through the appendiceal wall was observed. 


\section{Case Reports in Case Rep Gastroenterol 2018;12:551-555

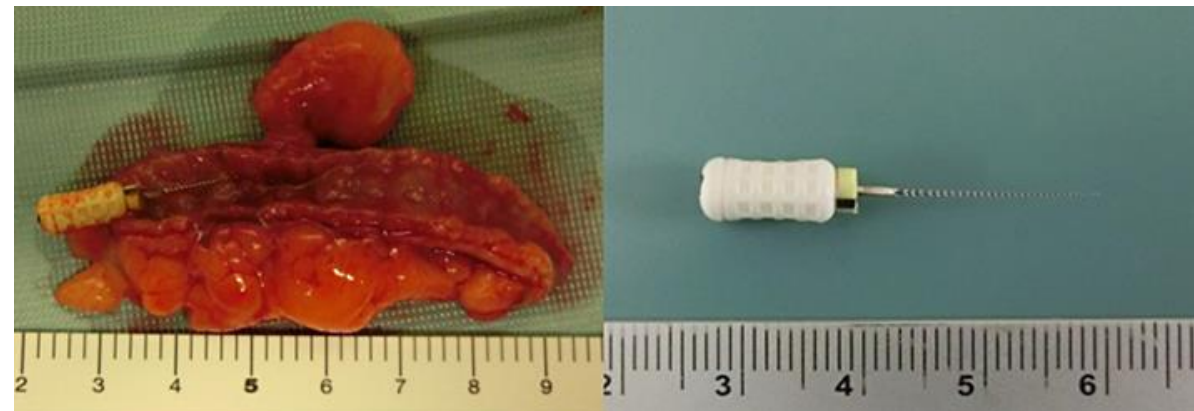

Fig. 3. A titanium dental instrument (reamer) for root canal treatment. 